\title{
Mass fractionation of noble gases in synthetic methane hydrate: Implications for naturally occurring gas hydrate dissociation
}

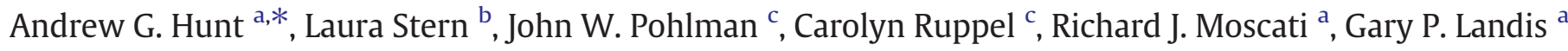 \\ a U.S. Geological Survey, Noble Gas Laboratory, Denver Federal Center, Denver, CO 80225, USA \\ ${ }^{\mathrm{b}}$ U.S. Geological Survey, 345 Middlefield Rd., MS 977, Menlo Park, CA 94025, USA \\ c U.S Geological Survey, 384 Woods Hole Rd, Wood Hole, MA 02543, USA
}

\section{A R T I C L E I N F O}

\section{Article history:}

Accepted 23 September 2012

Available online 29 September 2012

\section{Keywords:}

Gas hydrate

Noble gas

Methane

Stable isotopes

Mass-fractionation

\begin{abstract}
A B S T R A C T
As a consequence of contemporary or longer term (since $15 \mathrm{ka}$ ) climate warming, gas hydrates in some settings may presently be dissociating and releasing methane and other gases to the ocean-atmosphere system. A key challenge in assessing the impact of dissociating gas hydrates on global atmospheric methane is the lack of a technique able to distinguish between methane recently released from gas hydrates and methane emitted from leaky thermogenic reservoirs, shallow sediments (some newly thawed), coal beds, and other sources. Carbon and deuterium stable isotopic fractionation during methane formation provides a first-order constraint on the processes (microbial or thermogenic) of methane generation. However, because gas hydrate formation and dissociation do not cause significant isotopic fractionation, a stable isotope-based hydrate-source determination is not possible. Here, we investigate patterns of mass-dependent noble gas fractionation within the gas hydrate lattice to fingerprint methane released from gas hydrates. Starting with synthetic gas hydrate formed under laboratory conditions, we document complex noble gas fractionation patterns in the gases liberated during dissociation and explore the effects of aging and storage (e.g., in liquid nitrogen), as well as sampling and preservation procedures. The laboratory results confirm a unique noble gas fractionation pattern for gas hydrates, one that shows promise in evaluating modern natural gas seeps for a signature associated with gas hydrate dissociation.
\end{abstract}

Published by Elsevier B.V.

\section{Introduction}

As summarized by Ruppel (2011), recent studies indicate that methane hydrate may be dissociating due to contemporary warming of intermediate ocean waters that are impinging on continental slopes (e.g., Spitsbergen Margin; Westbrook et al., 2009) and in response to long term (since $15 \mathrm{ka}$ ) marine inundation and warming of permafrost on Arctic Ocean continental shelves (e.g., East Siberian Shelf; Shakhova and Semiletov, 2007 and Shakhova et al., 2010). For the Arctic shelf in particular, constraining the component of methane emissions directly attributable to gas hydrate dissociation is critical since this methane is more likely to reach the atmosphere without being dissolved in seawater (McGinnis et al., 2006) or oxidized (e.g., Ruppel, 2011) in the shallow water column. In such settings, total methane emissions can include components from deep-seated conventional-hydrocarbon reservoirs, submerged coal beds, shallow marine sediments where microbial methane production is ramping up, newly thawed sediments containing older organic carbon now available to fuel microbial

\footnotetext{
* Corresponding author at: USGS, Denver Federal Center, Bld 95, MS963, Denver, CO 80225, USA.

E-mail address: AHUNT@usgs.gov (A.G. Hunt).
}

methane production, and dissociating methane hydrates within and beneath the subsea permafrost. Methane release from each source is subject to different geologic, climatic and biogeochemical controls.

The sheer volume of methane sequestered in the climatesusceptible component of the global gas hydrate reservoir renders identification of the component of methane emissions attributable to dissociating gas hydrate of particular importance (Ruppel, 2011). The IPCC (2007) estimates that dissociating gas hydrate is the source of $\sim 2 \%$ of contemporary atmospheric methane, but proof is lacking because a technique for sourcing methane to gas hydrate dissociation has not been systematically developed. Methane hydrate can form from any microbial or thermogenic methane that is within the gas hydrate stability field and able to combine with free water. Widely applied stable isotope analyses that are routinely used to distinguish microbial and thermogenic methane sources are not suitable for determining whether methane emissions originate in recently dissociated gas hydrate. This is because methane enters and leaves the gas hydrate lattice without being isotopically altered (Hachikubo et al., 2007; Luzi et al., 2011). Thus, the best hope for distinguishing methane derived from recently dissociated gas hydrate from other populations of methane is development of a technique that can exploit unique characteristics of the methane recently released from gas hydrates. Noble gases preferentially partition by molecular 
weight (Barrer and Ruzicka, 1962; Barrer and Edge, 1967) in the gas hydrate lattice, but do not have such a predictable relationship in other gas populations. Noble gas analyses might therefore be used to "fingerprint" methane emissions.

This paper addresses the knowledge gap associated with identifying gas derived from dissociating methane hydrate by outlining the first steps in exploiting noble gas signatures to fingerprint these gas mixtures. Here, we use synthetic methane hydrate samples that are formed, stored, and degassed under controlled conditions and freshly-sampled natural gas hydrates from a deepwater marine setting to elucidate noble gas signatures associated with gas hydrate dissociation.

\section{Background}

Selective enclathration of noble gases in synthetic gas hydrates has been recognized since the work of Barrer and Ruzicka (1962) and Barrer and Edge (1967). Their studies demonstrated that xenon (Xe) and krypton (Kr) were enriched relative to argon $(\mathrm{Ar})$ in hydratederived gases and indicated that helium $(\mathrm{He})$ and neon $(\mathrm{Ne})$ could be removed relative to Ar at low temperature (Barrer and Edge, 1967). In a study of naturally occurring methane hydrate, Chersky and Tsarev (1999) noted that He was absent in the gas-hydrate crystal structure and enriched in the residual gas associated with the hydrate formation. Ginsburg et al. (1990, 1992, 1993) noted low He concentrations from hydrate-derived gases from the Okhotsk, Caspian, and Black seas.

Two recent studies present contradictory results regarding the reliability of using this mass-based noble gas fractionation as a fingerprinting tool for hydrate-derived methane emissions. Dickens and Kennedy (2000) analyzed samples obtained from Blake Ridge (ODP Leg 164), while Winckler et al. (2002) present data from near-seafloor samples recovered on Hydrate Ridge located on the U.S. Cascadian Margin. These studies are the only ones to focus on naturally occurring gas hydrate.

Noble gas data are expressed as F values, where $F i$ equals the isotope ratio of component $i\left({ }^{4} \mathrm{He},{ }^{20} \mathrm{Ne},{ }^{40} \mathrm{Ar},{ }^{84} \mathrm{Kr}\right.$ or $\left.{ }^{132} \mathrm{Xe}\right)$ to argon-36 $\left({ }^{36} \mathrm{Ar}\right)$ of the sample normalized to the atmospheric ratio of component $i$ to ${ }^{36} \mathrm{Ar}$. The ratios of $\mathrm{F}^{20} \mathrm{Ne}$ and $\mathrm{F}^{84} \mathrm{Kr}$ are plotted against $\mathrm{F}^{132} \mathrm{Xe}$ from the methane hydrate samples reported by Dickens and Kennedy (2000) and Winckler et al. (2002), as shown in Fig. 1.

The figure includes four isotopic components of noble gas isotopes $\left({ }^{20} \mathrm{Ne},{ }^{36} \mathrm{Ar},{ }^{84} \mathrm{Kr}\right.$ and $\left.{ }^{132} \mathrm{Xe}\right)$ to examine degrees of mass fractionation relative to ${ }^{36} \mathrm{Ar}$. The data from Winckler et al. (2002), which were originally reported as total elemental composition, have been recalculated to assume an air-like isotopic composition of the noble gas isotopic components in order to compare their results to other data sets presented in this study.

The Dickens and Kennedy (2000) data show a relatively small shift of $\mathrm{F}^{20} \mathrm{Ne}$ and $\mathrm{F}^{84} \mathrm{Kr}$ values from an atmospheric composition end member with increasing $\mathrm{F}^{132} \mathrm{Xe}$. The $\mathrm{F}^{20} \mathrm{Ne}$ data falls between atmospheric and solubility constraints, with two samples showing sizable amounts of excess ${ }^{132} \mathrm{Xe}$ (greater than could be explained by solubility fractionation). One sample plotted greater than solubility values for $\mathrm{F}^{84} \mathrm{Kr}$, the other at near solubility values for $\mathrm{F}^{84} \mathrm{Kr}$. Winckler et al. (2002) report higher $\mathrm{F}^{132} \mathrm{Xe}$ and $\mathrm{F}^{84} \mathrm{Kr}$ with much lower $\mathrm{F}^{20} \mathrm{Ne}$ values $(\sim 0.06$ to 0.02 ) that suggest extensive loss of light isotopes relative to atmospheric and air saturated sea water (ASSW). This trend is evidence for selective loss of ${ }^{20} \mathrm{Ne}$ during enclathration, as suggested by Barrer and Edge (1967). Mass dependent fractionation is further demonstrated in the $\mathrm{F}^{4} \mathrm{He}$ values reported by Winckler et al. (2002) (e.g., $\mathrm{F}^{4} \mathrm{He}$ from 0.006 to 0.097 ) as compared to Dickens and Kennedy (2000), who report appreciable amounts of ${ }^{4} \mathrm{He}$ ( $\mathrm{F}^{4} \mathrm{He}$ from 1.5 to 350 ). Winckler and coworkers speculate that the data from Dickens and Kennedy (2000) reflect contamination by air during sampling and storage in liquid nitrogen $\left(\mathrm{LN}_{2}\right)$ prior to analysis. The shipboard techniques used by Winckler et al. (2002) were designed to avoid this issue. However, this explanation does not account for the extreme He enrichments and the two samples with higher $\mathrm{F}^{84} \mathrm{Kr}$ and $\mathrm{F}^{132} \mathrm{Xe}$ values displayed by some of the data from Dickens and Kennedy (2000) (Fig. 1).

The purpose of our study is to investigate the systematic fractionation of noble gas compositions during the formation and dissociation of methane hydrate in controlled laboratory conditions, and, furthermore, to evaluate whether handling and storage procedures affect the measured compositions. Our goal is to relate the laboratory fractionation data to those from natural methane seeps and to determine if
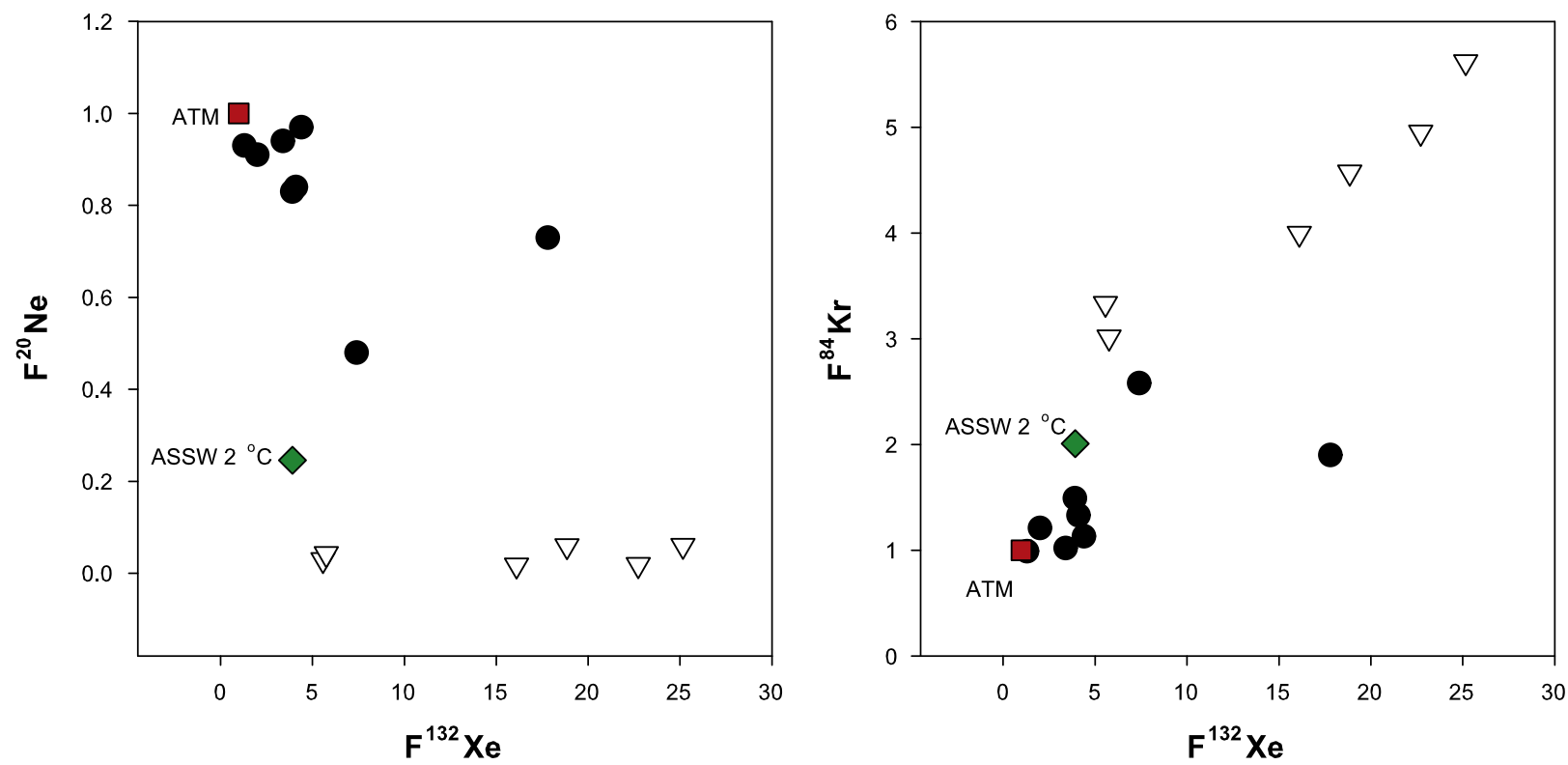

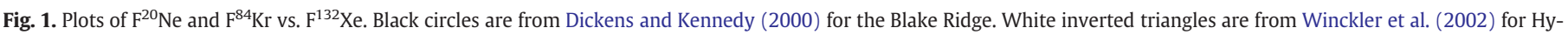
drate Ridge. Red square denotes an atmosphere sample, and the green diamond is air saturated sea water (ASSW) at $2{ }^{\circ} \mathrm{C}$. 
noble gas methods hold promise for distinguishing gases derived from recently dissociated gas hydrates from other sources (e.g., seeps).

\section{Methods}

The experimental methods are designed to evaluate the general encapsulation of noble gases during the synthesis and eventual dissociation of lab-formed methane hydrate, as well as changes incurred during long-term storage in $\mathrm{LN}_{2}$. We produced two splits of synthetic hydrate, one control (Noble 1) and one for additional processing (Noble 2). The control sample was dissociated in situ in the sample chamber after synthesis without contamination from room air. The companion sample was isolated after synthesis, removed from the apparatus, and stored in $\mathrm{LN}_{2}$ for 9 months prior to dissociation. The full procedure is detailed below.

\subsection{Synthesis procedure}

Methane hydrate was synthesized using a modified version of the ice seed method (Stern et al., 1996, 2004). This technique involves warming and static conversion of pressurized gas and $\mathrm{H}_{2} \mathrm{O}$ ice grains $(<250 \mu \mathrm{m})$ to gas hydrate. For this experiment, the pressurized gas was a mixture of two commercially available gases: reagent-grade methane spiked with 200 ppm He and pressurized air with uniform noble gas content. To obtain reproducible amounts of noble gases in the final mixture, we mixed the gases to $\sim 30 \mathrm{MPa}$ and $250 \mathrm{~K}$ at an approximate ratio of $85: 15$ methane-to-air in a $900 \mathrm{~cm}^{3}$ synthesis assembly. Two pre-chilled sample chambers with internal thermocouples were packed with identical masses of granular ice made from triple distilled water. The samples were attached to the synthesis apparatus, evacuated for $\sim 90 \mathrm{~s}$ to remove air between the ice grains, and then flooded with the source gas mixture. The gas-ice mixture equilibrated to $\sim 20 \mathrm{MPa}$ at $250 \mathrm{~K}$, and was then warmed by raising the temperature of an external fluid bath $\sim 10 \mathrm{~K} / \mathrm{h}$ to $\sim 287 \mathrm{~K}$. The pressure of the mixture was $\sim 30 \mathrm{MPa}$. These pressuretemperature conditions are deep within the methane hydrate stability field and well above the $\mathrm{H}_{2} \mathrm{O}$ ice melting point. Under these conditions, most hydrate formation occurs during the first heating stage (Circone et al., 2005 and Stern et al., 1996, 2004); however, additional heating/ cooling cycles through the ice point were performed to ensure full reaction. The thermocouples embedded within the samples were also used to monitor the extent of reaction. Aliquots of head space gas were collected both before and after reaction.

\subsection{Dissociation procedure}

Following synthesis, Noble 1 was dissociated by isolating the pressurized sample from the apparatus and placing it in a precision low-temperature Hart fluid bath. All portions of the transfer system were fully evacuated prior to sample introduction. Pressure in the synthesis apparatus was vented to just above $0.1 \mathrm{MPa}$ to relieve excess gas pressure while preventing any infiltration of atmospheric air. Starting at $\sim 220 \mathrm{~K}$, Noble 1 was then slowly dissociated in multiple steps, while aliquots of the released gas were repeatedly captured. The temperature was slowly raised as dissociation slowed. During the final step, temperature was raised through the ice point to release and collect any residual gas within the sample.

For the $\mathrm{LN}_{2}$ storage experiment (Noble 2), the sample was separated from the synthesis apparatus and then gradually depressurized to atmospheric pressure while being simultaneously cooled with $\mathrm{LN}_{2}$ to $\sim 130 \mathrm{~K}$. The final pressure-temperature conditions in the sample chamber remained within the gas hydrate stability field. The sample was then fully vented, cooled to $77 \mathrm{~K}$, removed from the sample vessel, wrapped in $\mathrm{Al}$ foil, and stored in $\mathrm{LN}_{2}$. After 9 months, Noble 2 was removed from storage, placed back into a chilled pressure vessel, and attached to the dissociation station. Following brief evacuation to remove air and/or $\mathrm{N}_{2}$ gas from the chamber, Noble 2 was then dissociated in a similar step-wise manner as Noble 1.

For both samples, temperature was closely controlled by the Hart fluid bath and monitored with internal thermocouples. Valves and pressure gauges on the dissociation station permitted careful monitoring of pressure throughout each collection and full evacuation of various portions of the system as necessary. The dissociated gas was collected into a series of 50-cc stainless steel cylinders (rated $1800 \mathrm{psi}$ ) and small $\mathrm{Cu}$ tubes (loaded to 5 to $15 \mathrm{psi}$ ). Gas samples in the copper tubes were then shipped to the USGS Noble Gas Laboratory in Denver, CO for noble gas analysis.

\subsection{Sample analysis}

For bulk gas and noble gas analyses, copper tube splits were attached to an ultra-low vacuum extraction line that was pumped down to pressures less than $1.3 \times 10^{-11} \mathrm{MPa}$. The tube was then opened and sample gas expanded through two co-axial dry ice-ethanol traps ( 200 K) into the extraction line. A split of the sample was measured for major gas compositions $\left(\mathrm{CH}_{4}, \mathrm{~N}_{2}\right.$, and $\left.\mathrm{O}_{2}\right)$ on a calibrated quadrupole mass spectrometer run in dynamic analysis mode. The sample gas was then exposed to an aluminum zirconium (AlZr) trap heated to $632 \mathrm{~K}$ to remove the reactive gases, thus producing a homogenized noble gas fraction. An aliquot of this fraction was used to simultaneously measure $\mathrm{Ar}$ $\mathrm{Kr}$ and Xe isotopes on a MAP 215-50 magnetic sector mass spectrometer. To fully separate Ar-Kr-Xe fraction from $\mathrm{He}$ and $\mathrm{Ne}$ fractions, the remaining sample fraction was exposed to successive cryogenic traps ( $\mathrm{LN}_{2} /$ charcoal and helium cryostat). Both He and Ne fractions were successively released from the helium cryostat and measured separately on the MAP 215-50 for quantitative isotopic compositions. Data for the calculation of gas and isotopic compositions were compiled from calibration curves from successive aliquots of an in-house air standard analyzed in a similar fashion to the samples. Reported errors represent the reproducibility of the air standards to the generated calibration curves.

\section{Results}

The results of the gas analyses are presented in Table 1. Gas concentrations for $\mathrm{CH}_{4}, \mathrm{~N}_{2}, \mathrm{O}_{2}$ and ${ }^{36} \mathrm{Ar}$ are presented as well as the calculated $\mathrm{F}$ values for ${ }^{4} \mathrm{He},{ }^{20} \mathrm{Ne},{ }^{40} \mathrm{Ar},{ }^{84} \mathrm{Kr}$ and ${ }^{132} \mathrm{Xe}$. Also reported here is the helium isotopic composition as $R / R_{A}$, where $\mathrm{R} / \mathrm{R}_{\mathrm{A}}$, is the ${ }^{3} \mathrm{He} /{ }^{4} \mathrm{He}$ ratio of the sample normalized to ${ }^{3} \mathrm{He} /{ }^{4} \mathrm{He}$ ratio of the atmosphere $\left(1.384 \times 10^{-6}\right.$, [Ozima and Podosek (2002)]).

In almost all cases, the measured isotopic compositions of $\mathrm{Ne}$ $\left({ }^{22} \mathrm{Ne} /{ }^{20} \mathrm{Ne},{ }^{21} \mathrm{Ne} /{ }^{20} \mathrm{Ne}\right)$, Ar $\left({ }^{40} \mathrm{Ar} /{ }^{36} \mathrm{Ar}\right), \operatorname{Kr}\left({ }^{86} \mathrm{Kr} /{ }^{84} \mathrm{Kr}\right)$ and $\mathrm{Xe}$ $\left({ }^{130} \mathrm{Xe} /{ }^{132} \mathrm{Xe}\right)$ (not shown) were indistinguishable from atmospheric values. The exception is that ${ }^{40} \mathrm{Ar} /{ }^{36} \mathrm{Ar}$ ratios from roughly 2 out of the 18 analyses showed notable variation beyond the reported laboratory error (Table 1). Presently, we cannot explain this variation, but note that the data did not vary systematically during the step release experiment and that the initial and final headspace gas measurements match the atmospheric composition $\left(\mathrm{F}^{40} \mathrm{Ar}=1\right)$.

\subsection{Initial vs. final headspace compositions}

Comparisons of the initial headspace gas to the final headspace gas (Table 1) show systematic decreases in all gas concentrations except $\mathrm{CH}_{4}$ and ${ }^{4} \mathrm{He}$. The mole fraction of $\mathrm{CH}_{4}$ in the headspace increases during gas hydrate formation due to preferential incorporation of the other gases into the gas hydrate lattice. The increase in ${ }^{4} \mathrm{He}$ most likely reflects exclusion of He during gas hydrate formation. These data confirm previous studies by Barrer and Ruzicka (1962), Barrer and Edge (1967) and Chersky and Tsarev (1999) demonstrating encapsulation of $\mathrm{N}_{2}, \mathrm{O}_{2}, \mathrm{Ar}, \mathrm{Kr}$ and $\mathrm{Xe}$ and exclusion of He in gas hydrates. In contrast to Barrer and Ruzicka (1962) and Barrer and Edge (1967), the headspace concentration Ne decreases slightly (calculated from 
Table 1

Gas compositions from synthetic hydrate experiments.

\begin{tabular}{|c|c|c|c|c|c|c|c|c|c|c|}
\hline Sample/incremental step & $\mathrm{CH}_{4} \mathrm{cc} / \mathrm{cc}$ & $\mathrm{N}_{2} \mathrm{cc} / \mathrm{cc}$ & $\mathrm{O}_{2} \mathrm{cc} / \mathrm{cc}$ & ${ }^{36} \mathrm{Ar} \mathrm{cc} / \mathrm{cc}\left(\times 10^{-6}\right)$ & $\mathrm{F}^{4} \mathrm{He}$ & $\mathrm{F}^{20} \mathrm{Ne}$ & $\mathrm{F}^{40} \mathrm{Ar}$ & $\mathrm{F}^{86} \mathrm{Kr}$ & $\mathrm{F}^{132} \mathrm{Xe}$ & $\underline{\mathrm{R} / \mathrm{R}_{\mathrm{A}}}$ \\
\hline Initial gas & 0.826 & 0.136 & 0.036 & 5.548 & 205.2 & 0.765 & 0.997 & 0.996 & 0.914 & 0.053 \\
\hline Final head space gas & 0.950 & 0.039 & 0.010 & 1.533 & 1152.5 & 1.241 & 1.009 & 0.867 & 0.657 & 0.045 \\
\hline Noble $1-1$ & 0.948 & 0.040 & 0.010 & 1.574 & 827.7 & 0.948 & 0.986 & 0.780 & 0.607 & 0.039 \\
\hline Noble $1-2$ & 0.970 & 0.023 & 0.007 & 0.997 & 450.4 & 0.805 & 0.986 & 1.469 & 1.102 & 0.044 \\
\hline Noble $1-3$ & 0.971 & 0.022 & 0.006 & 0.972 & 185.6 & 0.594 & 1.400 & 1.577 & 1.406 & 0.045 \\
\hline Noble 1-4 & 0.973 & 0.021 & 0.006 & 0.917 & 67.7 & 0.438 & 0.990 & 1.645 & 1.874 & 0.048 \\
\hline Noble $1-5$ & 0.968 & 0.024 & 0.007 & 1.051 & 36.7 & 0.486 & 1.006 & 1.606 & 1.438 & 0.046 \\
\hline Noble 1-6 & 0.969 & 0.024 & 0.007 & 1.020 & 71.9 & 0.582 & 1.008 & 1.547 & 1.352 & 0.044 \\
\hline Noble 1-7 & 0.971 & 0.022 & 0.006 & 0.953 & 12.2 & 0.424 & 0.995 & 1.551 & 1.501 & 0.059 \\
\hline Noble 1-8 & 0.979 & 0.016 & 0.005 & 0.709 & 6.8 & 0.092 & 1.004 & 1.820 & 2.728 & 0.050 \\
\hline Noble 2-1 & 0.972 & 0.024 & 0.005 & 1.107 & 307.0 & 0.446 & 0.994 & 1.133 & 1.641 & 0.045 \\
\hline Noble $2-2$ & 0.970 & 0.023 & 0.006 & 1.022 & 271.8 & 0.566 & 1.098 & 1.292 & 2.080 & 0.044 \\
\hline Noble $2-3$ & 0.978 & 0.018 & 0.005 & 0.905 & 100.4 & 0.401 & 1.042 & 1.545 & 2.452 & 0.044 \\
\hline Noble 2-4 & 0.984 & 0.016 & 0.000 & 0.718 & 37.3 & 0.330 & 1.195 & 1.972 & 3.044 & 0.043 \\
\hline Noble 2-5 & 0.985 & 0.016 & 0.000 & 0.868 & 7.4 & 0.194 & 0.948 & 1.628 & 2.522 & 0.050 \\
\hline Noble 2-6 & 0.983 & 0.015 & 0.002 & 0.766 & 1.6 & 0.179 & 1.052 & 1.930 & 2.848 & 0.085 \\
\hline Noble 2-7 & 0.983 & 0.014 & 0.004 & 0.811 & 0.6 & 0.192 & 1.003 & 1.680 & 2.743 & 0.185 \\
\hline Noble 2-8 & 0.982 & 0.015 & 0.004 & 0.862 & 0.2 & 0.179 & 0.952 & 1.652 & 2.721 & 0.389 \\
\hline Atmosphere & & 0.781 & 0.210 & 31.5 & 1.000 & 1.000 & 1.000 & 1.000 & 1.000 & 1.000 \\
\hline Laboratory error & $1.00 \%$ & $0.32 \%$ & $1.63 \%$ & $0.96 \%$ & $1.00 \%$ & $1.70 \%$ & $0.96 \%$ & $3.50 \%$ & $4.30 \%$ & $0.50 \%$ \\
\hline
\end{tabular}

Notes: 1 . Gas concentrations are reported in standard temperature and pressure $\left(273.2^{\circ} \mathrm{K}, 1\right.$ atmosphere).

2. $\mathrm{cc}=$ cubic centimeter.

3. $\mathrm{Fi}=\mathrm{i} /{ }^{36} \mathrm{Ar}$ (sample) normalized to $\mathrm{i} /{ }^{36} \mathrm{Ar}$ (atmosphere).

4. $\mathrm{R} / \mathrm{R}_{\mathrm{A}}={ }^{3} \mathrm{He} /{ }^{4} \mathrm{He}$ (sample) normalized to ${ }^{3} \mathrm{He} /{ }^{4} \mathrm{He}$ (atmosphere) $\left(1.384 \times 10^{-6}\right)$

$\mathrm{F}^{20} \mathrm{Ne}$ and ${ }^{36} \mathrm{Ar}$ concentration, Table 1$)$, which indicates incorporation of Ne within the hydrate structure. From these data, we demonstrate that methane hydrate formed and sequestered $\mathrm{N}_{2}, \mathrm{O}_{2}, \mathrm{Ne}, \mathrm{Ar}, \mathrm{Kr}$ and Xe in the closed synthesis apparatus.

A rough mass balance calculation from the initial gas pressure of $20 \mathrm{MPa}$ (pressure at the time of sampling the initial headspace gas) down to a final pressure $17 \mathrm{MPa}$ (post hydrate formation), at uniform temperature $\left(254^{\circ} \mathrm{K}\right)$ and variable volume ( 0.9 to 0.759 to account for volume decrease with hydrate formation) yields a total loss of $2.4 \mathrm{~mol}$ of gas from the synthesis chamber to $120 \mathrm{~g}$ of water in the hydrate structure. In terms of mass balance of the gases with observed decreases $\left(\mathrm{N}_{2}, \mathrm{O}_{2},{ }^{20} \mathrm{Ne},{ }^{36,40} \mathrm{Ar},{ }^{84} \mathrm{Kr}\right.$ and $\left.{ }^{132} \mathrm{Xe}\right)$ in mole fraction from initial to final headspace composition, all indicate loss (molar decrease) in the headspace; however, despite the noted increase in mole fraction of $\mathrm{CH}_{4}$, there is still a net loss of $\mathrm{CH}_{4}$ from the headspace. ${ }^{4} \mathrm{He}$ is the only gas that appears to experience a minor increase in the residual headspace gas, an interpretation that we advance with caution. Minor changes in the change in pressure of the synthesis vessel can also produce a net loss of ${ }^{4} \mathrm{He}$ in the headspace, suggesting to us that ${ }^{4} \mathrm{He}$ could be encapsulated or excluded depending just on pressure variation.

One important feature that emerges from the mass balance approach is that solubility partitioning is discounted and gas encapsulation is supported as a method of gas loss. The calculated percent losses of $\mathrm{N}_{2}, \mathrm{O}_{2},{ }^{36},{ }^{40} \mathrm{Ar},{ }^{84} \mathrm{Kr},{ }^{132} \mathrm{Xe}$ are all approximately $80 \%$ of original gas concentrations, while $\mathrm{CH}_{4}$ only changes by $18 \%$. In terms of aqueous solubility, $\mathrm{N}_{2}, \mathrm{O}_{2}$, Ar, $\mathrm{Kr}$ and Xe have dramatically different solubility coefficients in water. In our experiment, they behave similarly, showing only minor mass fractionation and preserving near to the measured initial ratios from the initial headspace gas to the final head space gas (e..g. $\mathrm{N}_{2} / \mathrm{Ar}_{\text {initial }}=83.1, \mathrm{~N}_{2} / \mathrm{Ar}_{\text {final }}=84.3$ ). For $\mathrm{Ar}$ and $\mathrm{CH}_{4}$, which have similar solubility coefficients, the values should remain constant in the headspace gas if solubility-based partitioning controlled the loss. The opposite occurs in our experiments. ${ }^{36} \mathrm{Ar} / \mathrm{CH}_{4}$ values drop from $1.98 \times 10^{-3}$ in the initial head space to $4.81 \times 10^{-4}$ in the final headspace gas indicating that there is a preferential uptake of Ar over $\mathrm{CH}_{4}$ during the progression of the synthesis, a process that is not controlled by aqueous solubility.

\subsection{Hydrate step dissociation data}

The bulk gas composition from the Noble 1 (short-term) and Noble 2 (long-term) stored samples is $\sim 98 \% \mathrm{CH}_{4}, \sim 1.7 \% \mathrm{~N}_{2}$ and $\sim 0.3 \% \mathrm{O}_{2}$ and does not appreciably vary during the experiment (Table 1 ). The concentration of noble gases shows the greatest variability, changing with increasing step in the experiments.

\subsubsection{Gas release patterns from the step dissociation experiments}

The change in the ${ }^{36} \mathrm{Ar}$ concentrations between the initial and final headspace gas samples indicates that ${ }^{36} \mathrm{Ar}$ is sequestered during methane hydrate formation (Table 1). A similar, yet more complex, trend is observed in the step-dissociation experiments. The mole fraction of methane remains constant during both experiments (Noble 1 and Noble 2). In Fig. 2, the ratios of $\mathrm{N}_{2}\left(\times 10^{1}\right),{ }^{4} \mathrm{He}\left(\times 10^{-5}\right),{ }^{20} \mathrm{Ne}$ $\left(\times 10^{-8}\right),{ }^{36} \mathrm{Ar}\left(\times 10^{-6}\right),{ }^{84} \mathrm{Kr}\left(\times 10^{-8}\right)$, and ${ }^{132} \mathrm{Xe}\left(\times 10^{-9}\right)$ to $\mathrm{CH}_{4}$ are plotted vs. incremental step measurement for Noble 1 and Noble 2. Release curves show a flat plateau from incremental steps 2 through 7 (Fig. 2) for a majority of the ratios, except ${ }^{4} \mathrm{He} / \mathrm{CH}_{4}$ and ${ }^{20} \mathrm{Ne} / \mathrm{CH}_{4}$ which have decreasing values as hydrate dissociation continues to completion.

The concentration of ${ }^{36} \mathrm{Ar}$ in the first step of the dissociation for Noble 1 is similar to the concentration measured in the final head space gas for the experiment and may represent residual headspace gas present from the first dissociation step. Low concentrations in the last step of the dissociation experiment may represent possible depletion of the ${ }^{36} \mathrm{Ar}$ during the final stage of hydrate dissociation. The ratio ${ }^{36} \mathrm{Ar}$ to $\mathrm{CH}_{4}$ $\left(1.015 \times 10^{-6} \pm 5.1 \times 10^{-8}\right)$ for Noble 1 is uniform during the step dissociation experiment, which suggests ${ }^{36} \mathrm{Ar}$ and $\mathrm{CH}_{4}$ occupy similar lattice sites in the hydrate structure even though the mass balance calculation implied that ${ }^{36} \mathrm{Ar}$ was preferentially lost relative to $\mathrm{CH}_{4}$. For Noble 2 , the pattern of ${ }^{36} \mathrm{Ar}$ release from Noble 2 is also uniform relative to the $\mathrm{CH}_{4}$ content, but the overall ratio decreases to $0.866 \times 10^{-6} \pm$ $11.5 \times 10^{-8}$ over the same incremental release intervals (Step increments 2 through 7 ) (Fig. 2). This change in ${ }^{36} \mathrm{Ar}$ concentration is insignificant in terms of experimental error but is consistent with a minor loss of ${ }^{36} \mathrm{Ar}$ relative to $\mathrm{CH}_{4}$ over the 9 month storage period. In both samples, the release of $\mathrm{N}_{2},{ }^{84} \mathrm{Kr}$, and ${ }^{132} \mathrm{Xe}$ is uniform throughout the 


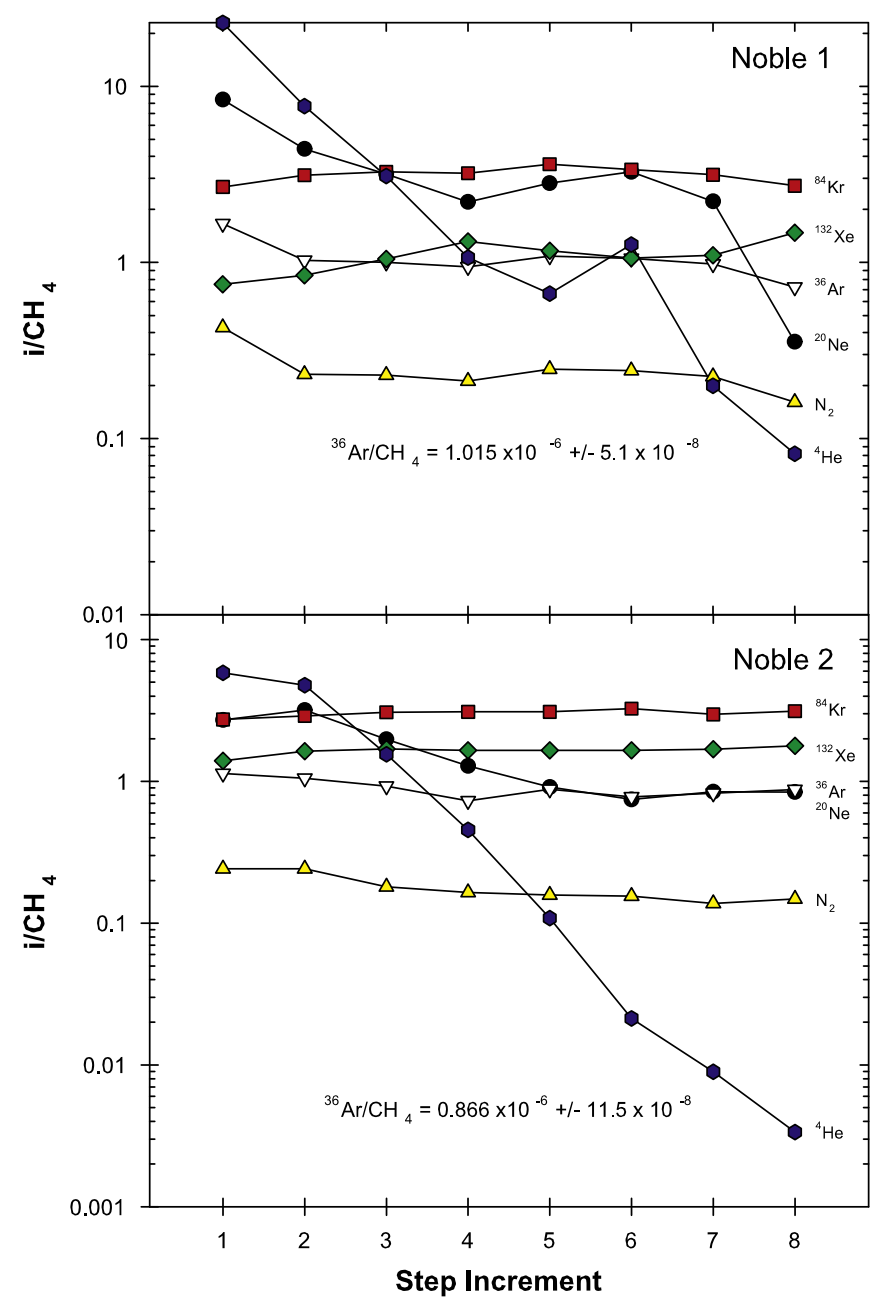

Fig. 2. $\mathrm{N}_{2},{ }^{4} \mathrm{He},{ }^{20} \mathrm{Ne},{ }^{36} \mathrm{Ar},{ }^{84} \mathrm{Kr}$, and ${ }^{132} \mathrm{Xe}$ concentrations normalized to $\mathrm{CH}_{4}$ from incremental step release of gas from the synthetic methane hydrate samples. Factors used to scale the normalized concentrations to fit the figure by $\mathrm{N}_{2}$ (yellow triangle) $\times 10^{1},{ }^{4} \mathrm{He}$ (blue hexagons) $\times 10^{-5},{ }^{20} \mathrm{Ne}$ (black circle) $\times 10^{-8},{ }^{36} \mathrm{Ar}$ (inverted white triangle) $\times 10^{-6},{ }^{84} \mathrm{Kr}$ (red square) $\times 10^{-8}$, and ${ }^{132} \mathrm{Xe}$ (green diamond) $\times 10^{-9}$.

dissociation process, while ${ }^{4} \mathrm{He}$ and ${ }^{20} \mathrm{Ne}$ are preferentially released during the early dissociation steps. The data at first approximation indicate a uniform release of the higher mass noble gases $\left({ }^{36} \mathrm{Ar}\right.$, ${ }^{84} \mathrm{Kr}$, and ${ }^{132} \mathrm{Xe}$ ) and methane and a continual depletion of the light nobles $\left({ }^{20} \mathrm{Ne}\right.$ and $\left.{ }^{4} \mathrm{He}\right)$ during hydrate dissociation. This trend is similar to the gas retention trend during hydrate formation (Section 4.1). The results suggest that ${ }^{4} \mathrm{He}$ and ${ }^{20} \mathrm{Ne}$ were retained by the hydrate structure during handling and storage, but were lost relatively rapidly during dissociation because they are more weakly retained in the hydrate lattice.

Cross-plots of noble gas ratios from the control sample step dissociation experiment (Noble 1 ) depict a distinct trend toward elevated $\mathrm{F}^{132} \mathrm{Xe}$ and lower $\mathrm{F}^{20} \mathrm{Ne}$ and higher $\mathrm{F}^{84} \mathrm{Kr}$ values during the dissociation process (Fig. 3). According to Barrer and Ruzicka (1962) and Barrer and Edge (1967), Ar, Kr, and Xe components are released from lattice sites of the methane hydrate, but $\mathrm{He}$ and $\mathrm{Ne}$ have small enough effective ionic radii that they should be absent. In our experiment, however, the concentrations of He and Ne are low, but not absent (Table 1), and the mass balance (Section 4.1) indicates that ${ }^{20} \mathrm{Ne}$ should be partially retained while ${ }^{4} \mathrm{He}$ should be low to absent. The dissociation trend in Fig. 3 reflects preferential loss of the trace ${ }^{4} \mathrm{He}$ and ${ }^{20} \mathrm{Ne}$ with progression of the step release. For ${ }^{84} \mathrm{Kr}$ and ${ }^{132} \mathrm{Xe}$, there is an increasing trend due to preferential release of ${ }^{84} \mathrm{Kr}$ and ${ }^{132} \mathrm{Xe}$ relative to ${ }^{36} \mathrm{Ar}$, which was shown to be fairly uniform in concentration throughout the incremental dissociation (Fig. 2). $\mathrm{N}_{2}$ to Ar ratios (calculated from Table 1) decrease with increasing step dissociation (88.2 down to 74.9), while $\mathrm{O}_{2}$ to $\mathrm{Ar}$ ratios maintain an almost consistent ratio of $22.5+/-0.2$ throughout the experiment, with the exception of step 3. Because the sample was purged between dissociation steps, the trend is not a fractional loss of headspace gas with increasing dissociation steps, but rather a direct product from hydrate dissociation. Overall, the trend suggests preferential loss of the lighter gases ( $\mathrm{He}, \mathrm{Ne}$, and $\mathrm{N}_{2}$ ) and retention of the heavier gases $\left(\mathrm{O}_{2}, \mathrm{Kr}\right.$ and $\left.\mathrm{Xe}\right)$ relative to $\mathrm{Ar}$ during gas hydrate dissociation.

There are two possible explanations for the trend of He and Ne depletion observed during step-dissociation (Fig. 3). One is that the He and $\mathrm{Ne}$ are being stored in non-lattice sites of the hydrate structure and released during physical rupture of these sites during the experiments. Alternately, the molecules are loosely held in the hydrate structure and diffuse from the solid with time (increasing step) in the experiment.

The possible storage of mass-fractionated gas in non-lattice sites is not consistent to the release pattern observed in the step dissociation experiments. Cryogenic scanning electron microscopy of synthetic hydrate shows numerous non-lattice voids (Stern et al., 2004). During the initial venting of the sample prior to dissociation (see Methods), audible "sample crackling" occurred and might indicate loss of non-lattice pore space gas from the hydrate. However, stoichiometry tests of synthetic hydrate indicate negligible storage of methane in non-lattice pore space (Stern et al., 2004), which in turn implies insignificant storage of $\mathrm{He}$ and $\mathrm{Ne}$ in the non-lattice hydrate volume fraction. For this study, we also packed the initial granular ice reactant more loosely than in previous experimental work, specifically to help reduce or avoid the problem of trapping gas in closed-off pores during synthesis. Thus, we discount the hypothesis that significant gas is released from non-lattice sites.

The second explanation is that the $\mathrm{He}$, Ne and possibly $\mathrm{N}_{2}$ components are loosely held in hydrate lattice sites. If gas from lattice and non-lattice hydrate sites is the source of the initial and final headspace gas components, there should be uniformity in the composition of light noble gases ( $\mathrm{He}$ and $\mathrm{Ne}$ ) coming from the hydrate dissociation. The concentration data from the Noble 1 dissociation show that ${ }^{84} \mathrm{Kr}$ and ${ }^{132} \mathrm{Xe}$ concentrations are fairly constant at $30.4 \pm 3.1\left(\times 10^{-9}\right)$ and $1.1 \pm 0.2\left(\times 10^{-9}\right) \mathrm{cc}(\mathrm{STP}) / \mathrm{cc}$, respectively, throughout step dissociation, while ${ }^{4} \mathrm{He}$ and ${ }^{20} \mathrm{Ne}$ concentrations decrease with each step. ${ }^{4} \mathrm{He}$ and ${ }^{20} \mathrm{Ne}$ from the late dissociation stage steps do not resemble the gas composition of the initial or final headspace gases (Fig. 3). This release pattern indicates a preferential loss of the light masses relative to the ${ }^{36} \mathrm{Ar}$ and suggests a possible diffusional release of the light gases $(\mathrm{He}, \mathrm{Ne})$ during dissociation. In this case, the primary release mechanism for the He and Ne could be diffusion from the undisturbed lattice sites and would occur with the change in chemical potential of the gases in the experiment and warming of the hydrate during dissociation. This would explain why the $\mathrm{F}^{4} \mathrm{He}$ and $\mathrm{F}^{20} \mathrm{Ne}$ ratios decrease throughout the dissociation process (Table 1 ) and produce the characteristic pattern of $\mathrm{F}^{4} \mathrm{He}$ decreases at a greater rate than $\mathrm{F}^{20} \mathrm{Ne}$ (Fig. 3). This characteristic pattern also cannot be derived by solubility partitioning; both He and Ne have similar solubility coefficients in water and should have a uniform ratio throughout the experiment if release was controlled by solubility portioning. The changing ratio of ${ }^{4} \mathrm{He}$ to ${ }^{20} \mathrm{Ne}$ over the step dissociation discounts solubility-based mass fractionation. As for the increasing values of $\mathrm{F}^{84} \mathrm{Kr}$ and $\mathrm{F}^{132} \mathrm{Xe}$, this could be an effect of ${ }^{36} \mathrm{Ar}$ diffusing at a rate slower than $\mathrm{He}$ and $\mathrm{Ne}$, but faster than the release of $\mathrm{Kr}$ and $\mathrm{Xe}$. If Ar is diffusing from the system, it cannot be determined from the data. Decreasing concentrations of ${ }^{36} \mathrm{Ar}$ during step dissociation may be an effect of mixing with the headspace gas and the hydrate end member gas. Although it is likely that diffusion controls the composition of the lighter noble gases, calculating diffusion coefficients for these gases is not possible with these experiments. 


\subsubsection{Helium isotopes}

The composition of helium isotopes (presented as $R / R_{A}$ ) from the hydrate dissociation experiments was similar to the initial gas composition prior to hydrate formation (Table 1). This would imply that there is little, if any, fractionation of helium isotopes during hydrate formation and that the hydrates preserve the initial helium isotopic condition of the parent gas. The only statistical deviation noted from the parent gas composition was observed in the late stages of the dissociation of Noble 2; here the isotopic compositions record a substantial $R / R_{A}$ increase from 0.053 to 0.389 (Table 1). The helium concentrations were the lowest of all the experiments $\left(<0.3 \%\right.$ of total ${ }^{4} \mathrm{He}$ in the hydrate), but well above that of the analytical blank. The increase in $R / R_{A}$ for the last incremental measurements is attributed to a procedural blank (atmospheric composition) associated with the lowest helium concentrations at the end of the dissociations mixing with the helium from the dissociation experiment.

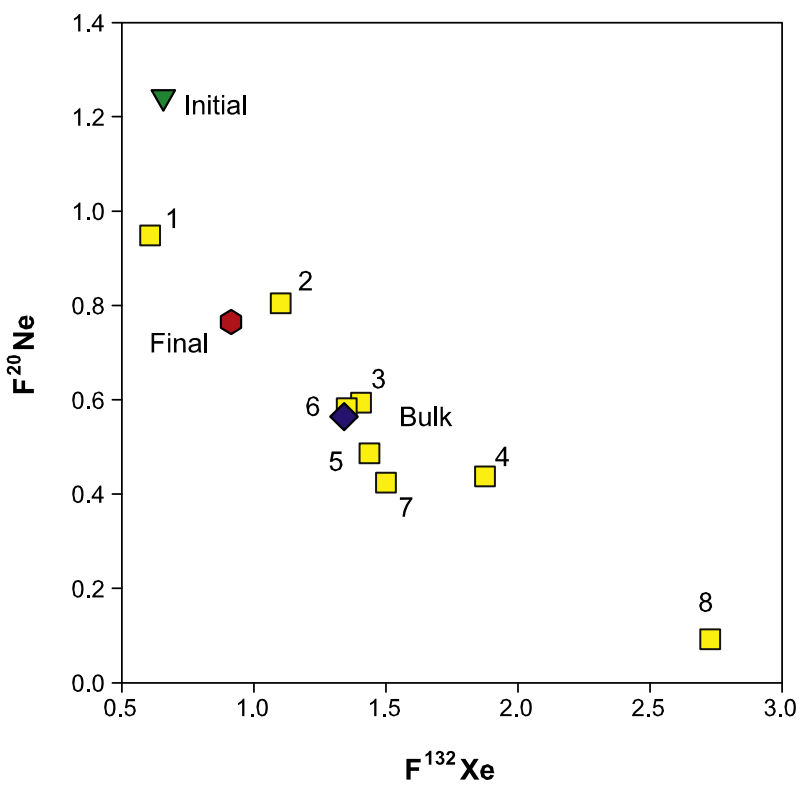

\subsection{Storage effects}

The concentrations of all gases in the sample stored in $\mathrm{LN}_{2}$ for 9 months (Noble 2) were generally lower than the control sample (Noble 1), which suggests gas loss during storage. Patterns of gas release in the dissociation experiment of the stored sample follow similar patterns for the control sample (Fig. 4), with an offset that favors either the loss of the lighter gases or retention of the heavier gases.

Included in Fig. 4 are calculated bulk values for the initial and final headspace gases for each dissociation experiment. The bulk values presented are an average value from the eight dissociation steps for each experiment and are thus an approximation to the data expected if the entire hydrate sample were dissociated in one step and measured as one sample. None of the bulk gas values from Noble 1 and Noble 2 are similar to each other even though the samples come from a split of the same synthesis experiment. The bulk values from the stored sample

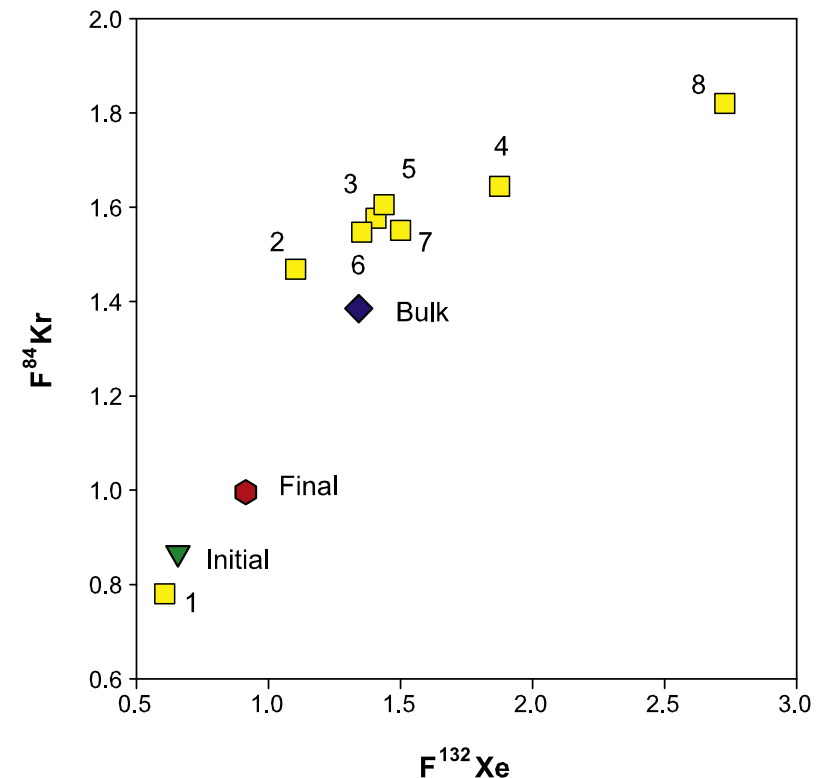

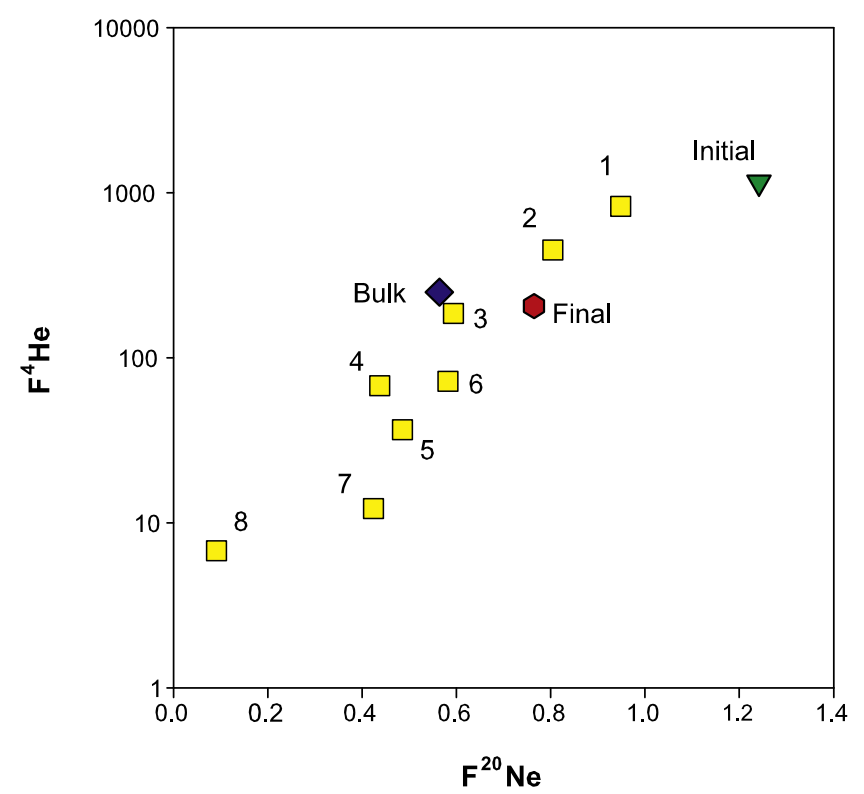

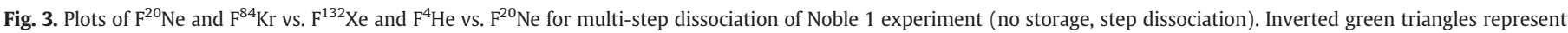

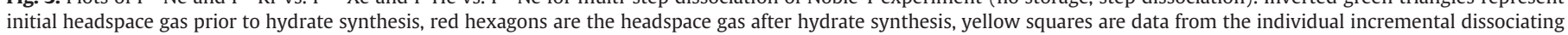
steps, and blue diamond is a calculated average of the incremental dissociation steps. Numbers label the step dissociation increment. 

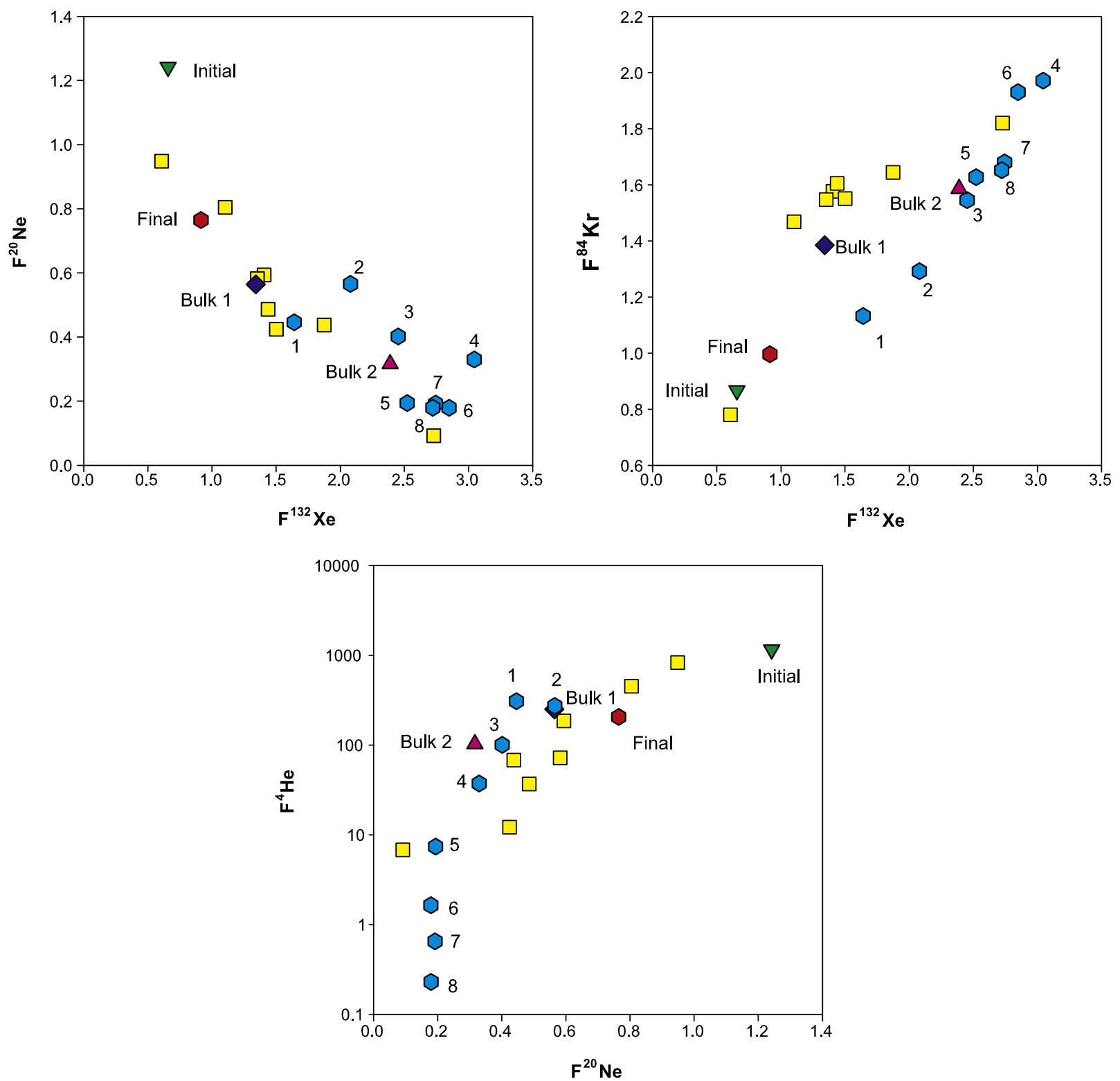

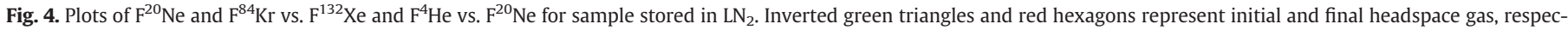

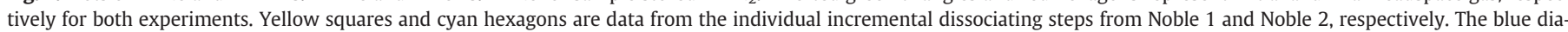

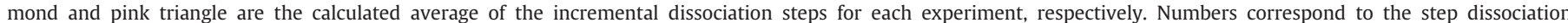
increment for Noble 2.

(Noble 2) reflect a loss of light noble gases relative to the heavier gases, probably during the storage phase. Lattice and non-lattice gas may also have been lost during the transfer from the synthesis vessel to $\mathrm{LN}_{2}$ and back to the dissociation vessel. As a preventive measure, the sample was maintained at very low temperature (near $77 \mathrm{~K}$ ) throughout the 1-minute transfer to minimize gas loss. Also, the step dissociation patterns and large amounts of He and Ne noted in the analyses preclude complete loss of the gases with storage by diffusion. Comparison of the bulk values for $\mathrm{F}^{4} \mathrm{He}$ and $\mathrm{F}^{20} \mathrm{Ne}$ from the controlled and stored sample shows a moderate decrease in both ${ }^{4} \mathrm{He}$ and ${ }^{20} \mathrm{Ne}$ with storage. The bulk $\mathrm{F}^{84} \mathrm{Kr}$ and ${ }^{132} \mathrm{Xe}$ values show much less change and actually increase with time. Because the $\mathrm{F}^{84} \mathrm{Kr}$ and ${ }^{132} \mathrm{Xe}$ values are normalized to ${ }^{36} \mathrm{Ar}$, increasing $\mathrm{F}^{84} \mathrm{Kr}$ and ${ }^{132} \mathrm{Xe}$ values suggest a loss of ${ }^{36} \mathrm{Ar}$ during storage. Averaging the total amount ${ }^{36} \mathrm{Ar}$ (Table 1 ) for each sample across the step dissociations shows a 10\% drop in total concentration in the stored sample as compared to the control and is the likely explanation for the increasing $\mathrm{F}$ values for ${ }^{84} \mathrm{Kr}$ and ${ }^{132} \mathrm{Xe}$ computed in the bulk gas values. This mass-driven drop in gas concentrations could be a result of a reordering of the hydrate structure during storage in $\mathrm{LN}_{2}$. Storage of gas hydrate samples in $\mathrm{LN}_{2}$ for periods longer than the 9-month duration of our experiment could produce greater detrimental effects on the interpretation of original noble gas composition associated with the stored gas hydrate.

\section{Emissions from naturally dissociating hydrates}

Building on the insight gained about noble gas fractionation patterns in synthetic methane hydrates under controlled conditions, we compare these laboratory-based results with published natural methane hydrate values (Dickens and Kennedy, 2000; Winckler et 
al., 2002), methane hydrate samples recently obtained from the Ulleung Basin, offshore Korea, and thermogenically derived hydrocarbons from the Elk Hills oil and gas fields (Torgersen and Kennedy, 1999). Fig. 5 compiles these results and the calculated bulk averages for Noble 1 and 2.

The results reflect different physical phenomena characteristic of the associated samples. For solubility based mass fractionation, the trend between atmospheric compositions and solubility values is well understood and documented. Torgersen and Kennedy (1999) explain that the pattern of decreasing $\mathrm{F}^{20} \mathrm{Ne}$ and increasing ${ }^{84} \mathrm{Kr}$ and ${ }^{132} \mathrm{Xe}$ for their conventional oil and gas samples is due to the enrichment of air-like (in isotopic composition) heavier noble gases from organic sources in the source rock of the hydrocarbon reservoir. This is manifested by the negative trend away from an initial composition assumed to be air-like gas and air-saturated water (formation water). The trend of $\mathrm{Kr}$ and Xe enrichment is very similar to that of the synthetic hydrate dissociation trend. Importantly, though, the amount of enrichment relative to ${ }^{36} \mathrm{Ar}$ is orders of magnitude higher that can be fractionated from hydrate derived from air-saturated water. This observation opens the possibility of distinguishing thermogenic gas contributions for initial hydrate formation, as well as for distinguishing between gas derived from dissociating methane hydrates from that emitted by leaky thermogenic reservoirs, shallow sediments and other sources.

The arrow in Fig. 5 shows the fractionation trend of $\mathrm{F}^{20} \mathrm{Ne}$ and $\mathrm{F}^{84} \mathrm{Kr}$ and $\mathrm{F}^{132} \mathrm{Xe}$ that we infer during the dissociation of the synthetic methane hydrate. The trend originates with an atmospheric composition that was used in initial headspace of the experiments and progresses to demonstrate enrichment of the ${ }^{84} \mathrm{Kr}$ and ${ }^{132} \mathrm{Xe}$ and depletion of ${ }^{20} \mathrm{Ne}$, all relative to ${ }^{36} \mathrm{Ar}$. The trend tracking the loss of the lighter noble gases from the hydrate is also manifest by the change in total concentration of ${ }^{36} \mathrm{Ar}$ from Noble 1 to Noble 2 and by the general loss of ${ }^{4} \mathrm{He}$ and ${ }^{20} \mathrm{Ne}$ early in all the step dissociation experiments (Figs. 3 and 4). This is the characteristic "fingerprint" of hydrate derived gas but also shares the characteristic of solubility-based partitioning as shown by the airsaturated seawater values in Fig. 5. Rather than a distinctive endmember composition for natural methane hydrate samples, we envision that there will be a range or trend of compositions that is dependent on the initial content of the pre-hydrate formation gas, the amount of gas incorporated into the hydrate structure, and the degree of dissociation of the hydrate. Taken together, these would fractionate the lighter noble gases from the heavier over changing time-pressuretemperature conditions. For our synthetic experiments, measured noble gas values all start with an atmospheric composition and progress toward a heavy noble gas enriched trend that follows the sequential loss of lighter noble gases with progressive dissociation. Although we prove that the mass partitioning is not solubility based in the experiments, the trend looks very similar to ASSW.

For the Winckler et al. (2002) data, the trends mostly reflect the impact of the technique used for sampling the hydrates. After selection of hydrate material, the samples were shaved and loaded into dissociation vessels and purged for long periods to ensure no atmospheric contamination (Winckler et al., 2002). During the initial purging, prior to sampling, we postulate that there was a fairly complete loss of $\mathrm{He}$ and $\mathrm{Ne}$, producing the clustering of data that supports late stage dissociation of the hydrates. If earlier samples had been taken, the data would follow a trend similar to the one that we observe for the synthetic samples, starting with a noble gas composition similar to air-saturated sea water, the presumed initial gas source for the noble gases, which is consistent with a microbial methane origin, as concluded by Winckler et al. (2002), with low He and Ne content in the formation gas. For the Dickens and Kennedy (2000) samples, the results do not follow a trend similar to the synthetic data. Rather, their results support Winckler's hypothesis and comments made by Dickens and Kennedy (2000) that the samples were contaminated with air during sampling or were possibly affected by storage and aging of the gas hydrate.

The Ulleung Basin gas hydrate sample (Collett et al., 2011) was obtained via controlled depressurization of methane hydrate bearing samples recovered using a pressure corer, which is designed to hold samples at in situ hydrostatic pressure starting at the moment of recovery from the seafloor formation. The gas samples were collected following strict sampling protocols to ensure that the gases would be suitable for later noble gas analyses. Trends in the resulting noble gas data shown in Fig. 5 resemble those observed in the synthetic samples, but they project back to an initial gas composition that is enriched in Xe
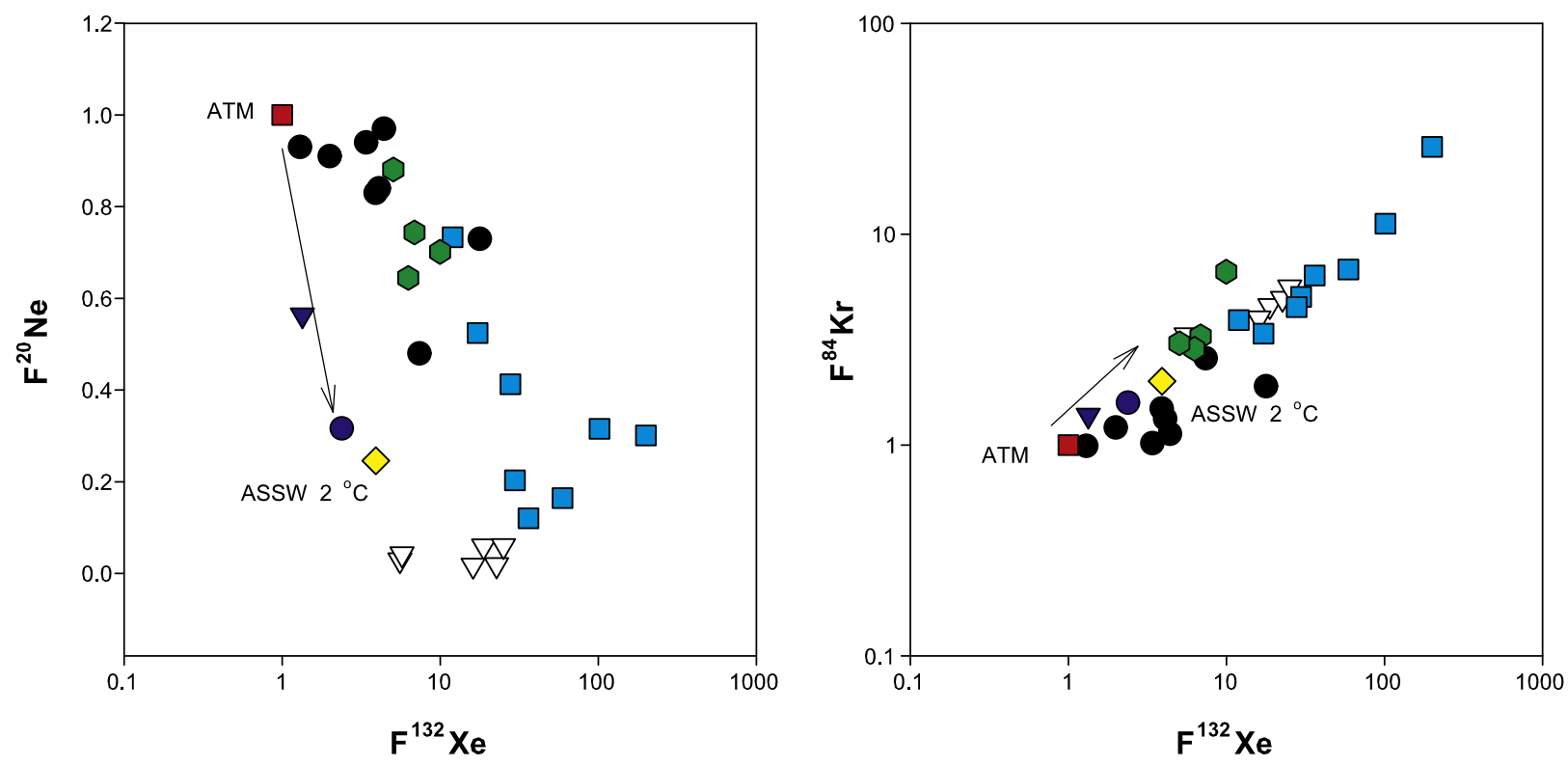

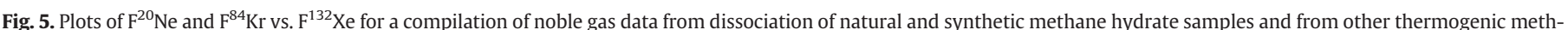

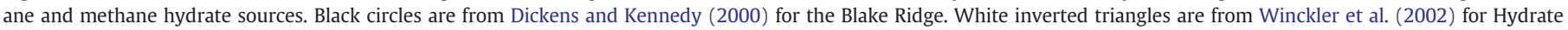

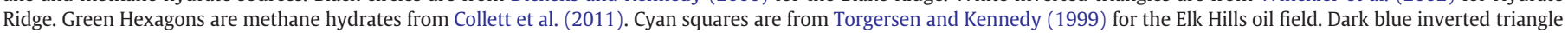
and circle are bulk values for Noble 1 and 2 respectively. Red square denotes an atmosphere sample, and the yellow diamond is ASSW at $2{ }^{\circ} \mathrm{C}$. 
and $\mathrm{Kr}$ compared to possible solubility conditions but depleted in Ne in assumed solubility conditions. One possible explanation could be that the noble gas composition originated as free gas that formed from the solubility based gas-fluid partitioning of air-saturated seawater. For the free gas phase of this process noble gases would be derived originally from ASSW that come to equilibrium with methane in a free gas phase. The light noble gases would enrich relative to $\mathrm{Ar}$ in the free gas, creating higher $\mathrm{F}$ values that trend from air saturated seawater to atmospheric compositions. The heavier gases would be retained in the fluid phase relative to Ar, thus decreasing their $\mathrm{F}$ values away from solubility values toward atmospheric values. If the free gas phase was incorporated into a methane hydrate, the $\mathrm{F}^{20} \mathrm{Ne}$ would decrease from free gas values while the $\mathrm{F}^{84} \mathrm{Kr}$ and $\mathrm{F}^{132} \mathrm{Xe}$ would both increase. In comparison to the noble gas compositions of the thermogenic derived methane from Torgersen and Kennedy (1999), trends of fractionation of light and heavy noble gases are similar but degree of differentiation is much less in the hydrate derived gases. This is distinctive but not completely conclusive; both patterns of fractionation are a result of different processes present (e.g. solubility partitioning followed by hydrate formation vs. solubility partitioning between water-oil-free gas) with only the scale of the fractionation distinguishing the two.

Noble gas ratios are a complementary tool to stable isotopes for identifying thermogenic gas contributions in gas hydrate studies. The most promising insight involves the fractionation patterns that reveal gas hydrate formation and dissociation mechanisms. More study of naturally occurring hydrates, including better constraints on source gases and hydrate formation mechanisms and implementation of recovery and sample storage methods appropriate for noble gas analyses, is required to advance towards establishing a "fingerprinting" technique.

\section{Conclusions}

Mass fractionation of noble gases in synthetic methane hydrate samples follows the observations of Winckler et al. (2002) in that there is enrichment of $\mathrm{Kr}$ and Xe relative to Ar. Low values of $\mathrm{F}^{4} \mathrm{He}$ and $\mathrm{F}^{20} \mathrm{Ne}$ are noted in both the natural and synthetic hydrates, but the hydrates may tend to store these gases in lattice sites or defects that retain $\mathrm{He}$ and $\mathrm{Ne}$ and then release these molecules diffusively during hydrate dissociation. These effects are important factors to consider when evaluating noble gas data from natural gas hydrate samples and when using noble gas data to fingerprint seep gas emissions.

$\mathrm{LN}_{2}$ storage demonstrably affects noble gas composition of gas hydrate stored over a 9-month period. The effects are likely to be more profound and less pronounced for longer and shorter-term storage in $\mathrm{LN}_{2}$, respectively. We recommend that natural hydrate samples be degassed immediately under controlled conditions that limit air contamination and into containers suitable for later noble gas analyses to ensure the best results for studying noble gas trends during gas hydrate dissociation.

This paper provides an initial step in developing a technique to fingerprint seep gases to determine whether they originate with gas hydrate dissociation. Further refinements will require better constraints on the initial source of gas sequestered in the natural hydrates, as well as a good understanding of the degree of gas hydrate dissociation that has occurred over time. Our understanding of gas release from the synthetic hydrates for this review only includes a hydrate formed from a free gas phase and cannot yet address the pattern of noble gas releases from a hydrate that formed from a gas phase dissolved in fluids. This formation process, which is common in nature, could significantly alter the sequestration of gases in the hydrate lattice, as well as the end products of dissociation. In theory, progressive dissociation of gas hydrates due to climate warming on upper continental slopes worldwide or on Arctic continental shelves might eventually be distinguished from other methane sources by monitoring changes in the noble gas patterns in methane emissions.

\section{Acknowledgments}

Partial support for this research was provided by Interagency Agreements DE-FE0002911 and DE-NT0006147 between the U.S. Geological Survey Gas Hydrates Project and the U.S. Department of Energy's Methane Hydrates Research and Development Program. We thank J. Pinkston (USGS) for the technical support during synthesis and dissociation of samples made in-house, and T. Lorenson (USGS) for help with dissociation of natural samples. We also thank T. Collett (USGS) and Ji-Hoon Kim (KIGAM) for the sample obtained from drilling in the Ulleung Basin. Any use of trade, firm, or product names is for descriptive purpose only and does not imply endorsement by the U.S. Government.

\section{References}

Barrer, R.M., Edge, A.V.J., 1967. Selective clathration during the formation of gas hydrates. Separation Science 2 (2), 145-154.

Barrer, R.M., Ruzicka, D.J., 1962. Non-stoichiometric clathrate compounds of water. Part 2. Formation and properties of double hydrates. Transactions of the Faraday Society 58, 2239.

Chersky, N.V., Tsarev, V.P., 1999. Osobennosty nakoplenija helija v rajonakh rasprostranenija mnogletnei merzloty. V Kn. "Geologicheskoe stroenie, perspectivy neftegasonosnosty Jakutskoj ASSR", 1972, JF SO AN SSSR pp 124-132 (in Russian) cited in Prasolov, E.M., et al., Helium and other noble gases in gas-hydrate sediments of the Hakon Mosby Mud Volcano. Geo-Marine Letters 19, 84-88.

Circone, S., Kirby, S.H., Stern, L.A., 2005. Direct measurement of methane hydrate composition along the hydrate equilibrium boundary. The Journal of Physical Chemistry B 109 (19), 9468-9475.

Collett, T.S., Kim, J., Hunt A.G., Ruppel, C., 2011. Noble gas data from pressure core of hydrate horizons in the Ulleung Basin, off shore Korea. Personal communication.

Dickens, G.R., Kennedy, B.M., 2000. Noble gases in methane hydrate from the Blake Ridge. In: Paull, C.K., Matsumoto, R., Wallace, P.J., Dillon, W.P. (Eds.), Proc. ODP, Sci. Results, 164. Ocean Drilling Program, College Station, TX, pp. 165-170. http://dx.doi.org/ 10.2973/odp.proc.sr.164.211.2000.

Ginsburg, G.D., et al., 1990. Filtrogenic gas hydrates in the Black Sea. Soviet Geology and Geophysics 31, 8-16.

Ginsburg, G.D., et al., 1992. Gas hydrates of the Southern Caspian. International Geology Review 13, 41-48.

Ginsburg, G.D., et al., 1993. Gas hydrates from the continental slope, offshore Sakhalin Island, Okhotsk Sea. Geo-Marine Letters 19, 57-67.

Hachikubo, A., Kosaka, T., Kida, M., Krylov, A., Sakagami, H., Minami, H., Takahashi, N. Shoji, H., 2007. Isotopic fractionation of methane and ethane hydrates between gas and hydrate phases. Geophysical Research Letters 34, 5.

Intergovernmental Panel on Climate Change (IPCC), 2007. Climate Change 2007: The Physical Basis. Cambridge University Press, New York.

Luzi, M., Schicks, J.M., Erzinger, J., 2011. Carbon Isotopic Fractionation of Synthetic Methane and Carbon Dioxide Hydrates. Proceedings of the 7th International Conference on Gas Hydrates (ICGH 2011), Edinburgh, Scotland, United Kingdom, July 17-21, 2011.

McGinnis, D.F., Greinert, J., Artemov, Y., Beaubien, S.E., Wüest1, A., 2006. Fate of rising methane bubbles in stratified waters: how much methane reaches the atmosphere? Journal of Geophysical Research 111, p15.

Ozima, M., Podosek, F.A., 2002. Noble Gas Geochemistry, 2nd ed. Cambridge University Press, Cambridge, UK.

Ruppel, C.D., 2011. Methane Hydrates and Contemporary Climate Change. Nature Education Knowledge (12), 12.

Shakhova, N., Semiletov, 2007. Methane release and coastal environment in the East Siberian Arctic shelf. Journal of Marine Systems 227-243.

Shakhova, N., Semiletov, I., Salyuk, A., Yusupov, V., Kosmach, D., Gustafsson, O., 2010 Extensive methane venting to the atmosphere from sediments of the East Siberian Arctic Shelf. Science 327, 1246-1250.

Stern, L.A., Kirby, S.H., Durham, W.B., 1996. Peculiarities of methane clathrate hydrate formation and solid-state deformation, including possible superheating of water ice. Science 273 (5283), 1843-1848.

Stern, L.A., Circone, S., Kirby, S.H., Durham, W.B., 2004. Scanning Electron Microscopy (SEM) investigations of laboratory-grown gas hydrates formed from melting ice, and comparison to natural hydrates. American Mineralogist 89 (8-9), 1162-1175.

Torgersen, T., Kennedy, B.M., 1999. Air-Xe enrichments in Elk Hills oil field gases; role of water in migration and storage. Earth and Planetary Science Letters 167 (3-4), 239-253.

Westbrook, G.K., Thatcher, K.E., et al., 2009. Escape of methane gas from the seabed along the West Spitsbergen continental margin. Geophysical Research Letters 36, L15608. http://dx.doi.org/10.1029/2009GL039191.

Winckler, G., Werner, A.-H., Holocher, J., Kipfer, R., Levin, I., Poss, C., Rehder, G., Suess, E. Schlosser, P., 2002. Noble gas and radiocarbon in natural gas hydrates. Geophysical Research Letters 29 (10), 4. 